\title{
KINERJA PROGRAM KELOMPOK USAHA MANDIRI (KUM) YAYASAN DANA SOSIAL AL-FALAH TERHADAP PERLINDUNGAN MAQASHID SYARIAH'
}

\author{
Lazuardi Azhari Laksono \\ Mahasiswa Program Studi S1 Ekonomi Islam-Fakultas Ekonomi dan Bisnis-Universitas Airlangga \\ Email : lazuardi.azhari-12@feb.unair.ac.id \\ Drs. R. M. Qudsi Fauzi, M.M. \\ Departemen Ekonomi Syariah-Fakultas Ekonomi dan Bisnis-Universitas Airlangga \\ Email : r-moh-q-f@feb.unair.ac.id
}

\begin{abstract}
This study is done to know the performance of Yayasan Dana Sosial Al-Falah Independent Business Groups (KUM) program toward maqashid syariah protection. The background of the study is accountability responsibility of LAZ over funding management of ZIS which entrusted to benefactor of LAZ especially YDSF. In this case, the quality of performance which talked about is the protection toward maqashid syariah which receives funding from Independent Business Groups program. This study is a qualitative research. The approach of this research uses case-study strategy. The data collection used in this study is interview method; after collecting data, it is continued with reducting data, presenting data, and drawing conclusion. The research shows that YDSF Independent Business Groups program with various activities within has a performance with good criteria. Its good performance is measured with protected several aspects from mustahiq of YDSF Independent Business Groups, those aspects are; religion, intellectual, and wealth.
\end{abstract}

\section{Keywords: Performance, Lembaga Zakat, Maqashid Syariah}

\section{Pendahuluan}

Zakat adalah kewajiban bagi setiap umat muslim, dan termasuk dalam rukun Islam yang ke empat. Namun yang diwajibkan untuk berzakat adalah muslim yang hartanya telah mencapai nishab saja (muzakki). Sedangkan muslim lainnya yang tidak mencapai nishab bisa jadi mereka termasuk golongan yang berhak menerima zakat (mustahia). Konsep zakat adalah mendistribusikan kekayaan dari muzakki kepada mustahik dengan jumlah dan kriteria tertentu. Konsep zakat yang sedemikian rupa inilah yang menjadikan zakat adalah bukan hanya sebagai sarana berhubungan kepada Allah SWT tetapi juga sebagai hubungan kepada manusia lain. Dengan berzakat akan menambah ${ }^{[1]} J u r n a l$ ini merupakan bagian Skripsi Lazuardi Azhari Laksono NIM 041211432006 yang diuji pada tanggal 2 Juni 2017

kualitas hubungan terhadap Allah SWT dan juga kepada manusia. Sebagaimana Allah SWT telah berfirman dalam Al-imran ayat 134:

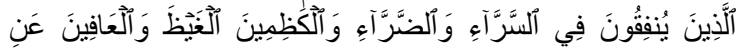

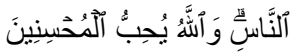

Al-Ladhina Yunfiqūna $\mathrm{Fl}$ As-Sarrāi Wa AđĐarrā'i Wa Al-Kāžimina Al-Ghayža Wa Al'Āfina 'Ani An-Nāsi Wa "̈Allāhu Yuhibbu AlMunsinina

Artinya: (yaitu) orang-orang yang menafkahkan (hartanya), baik di waktu lapang maupun sempit, dan orang-orang yang menahan amarahnya dan memaafkan (kesalahan) orang. Allah menyukai orang-orang yang berbuat kebajikan.

Selain zakat adapula infaq dan shadaqoh yang berbeda dengan zakat, infaq dan shadaqoh tidak menjadi kewajiban bagi umat muslim, sifatnya hanya sukarela, siapapun diperbolehkan 
Laksono, et al/Jurnal Ekonomi Syariah Teori dan Terapan Vol. 5 No. 6 Juni 2018: 467-482; KINERJA PROGRAM KELOMPOK USAHA MANDIRI YAYASAN DANA SOSIAL AL FALAH TERHADAP PERLINDUNGAN MAQASHID SYARIAH

untuk berinfaq dan shadaqoh tanpa ada batasan tertentu layaknya berzakat. Meskipun tidak menjadi kewajiban bagi muslim, infaq dan shadaqoh memiliki manfaat tertentu. Terlepas bahwa infaq shadaqoh tidak menjadi kewajiban bagi seorang muslim, namun Allah SWT menganjurkan umatnya untuk berinfaq dan bershadaqoh. Berikut hadits yang menerangkan mengenai baiknya infaq dan shadaqah.

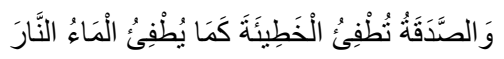

waś- sadaqata tuḍ̂i ulkhaḍilata kamā yuḍiılmā unnāro

Artinya: Sedekah itu akan memadamkan dosa sebagaimana air dapat memadamkan api. (HR. Tirmidzi no. 614) Maka dari itu Zakat, infaq, maupun shadaqoh, bila dilakukan akan memberikan dampak positif kepada yang menunaikannya, karena telah melaksanakan kewajiban zakat sebagai perintah Allah SWT dan infaq shadaqoh sebagai penyempurnanya. Begitu juga akan memberikan manfaat bagi mereka yang menerima atas zakat, infaq,dan shadaqoh tersebut.

Potensi zakat, infaq dan shadaqoh di Indonesia sangatlah besar mengingat bahwa Indonesia memiliki jumlah mayoritas penduduk muslim terbesar di dunia. Melihat potensi besar tersebut pemerintah menetapkan undang-undang tentang pengelolaan zakat yaitu undang-undang No. 23 Tahun 2011 yang sebelumnya adalah undang-undang No.38 tahun 1999. Dari undang-undang tersebut ditetapkan

BAZNAS sebagai lembaga pengelolaan zakat secara nasional. Sedangkan LAZ sebagai lembaga pembantu pengelolaan zakat yang dibentuk oleh masyarakat. Lalu terdapat UPZ sebagai satuan organisasi yang dibentuk BAZNAS untuk mengumpulkan zakat.

Untuk saat ini dana zakat yang terhimpun masih jauh dari potensi yang begitu besar tersebut. Bahkan sejumlah masyarakat masih menyalurkan zakatnya dengan mandiri atau belum melalui lembaga zakat. Hal ini menjadi pekerjaan rumah bagi lembaga zakat di indonesia agar masyarakat menyalurkan dana zakatnya melalui lembaga zakat, salah satu caranya yaitu dengan meningkatkan kinerja dari lembaga tersebut agar masyarakat mempercayai bahwa dana yang diberikan dikelola dengan baik.

Tabel 1.1

Total Pengumpulan ZIS Di Indonesia

\begin{tabular}{|c|c|}
\hline Tahun & Total Pengumpulan ZIS \\
\hline 2011 & $39.401 .992 .563,94$ \\
\hline 2012 & $50.220 .719 .886,92$ \\
\hline 2013 & $59.019 .259 .845,87$ \\
\hline 2014 & $82.947 .383 .165,39$ \\
\hline 2015 & $98.473 .103 .020,77$ \\
\hline
\end{tabular}

Sumber: pusat.baznas.go.id 2016

Dari data diatas ZIS yang terkumpul dari tahun 2011-2015 jumlah yang terkumpul masih jauh dari jumlah potensi yang ada. Namum sisi positifnya adanya kenaikan setiap tahunnya jumlah yang 
Laksono, et al/Jurnal Ekonomi Syariah Teori dan Terapan Vol. 5 No. 6 Juni 2018: 467-482; KINERJA PROGRAM KELOMPOK USAHA MANDIRI YAYASAN DANA SOSIAL AL FALAH TERHADAP PERLINDUNGAN MAQASHID SYARIAH

terhimpun tersebut. kenaikan tersebut menggambarkan bahwa kesadaran masyarakat dalam berzakat, infaq dan shadaqoh meningkat. Kenaikan tersebut juga menggambarkan semakin baiknya kinerja BAZNAS dalam mengumpulkan ZIS.

Kinerja yang baik pada lembaga zakat sangat penting, karena pada lembaga zakat mereka mengelola danadana yang telah disalurkan melalui mereka dan dipercayai akan terkelola dengan baik. Zakat adalah salah satu bentuk hubungan antara manusia dan Allah SWT dan mereka yang menunaikan zakat adalah salah satu bentuk ibadah. Lembaga zakat yang dipercayai para muzakki harus memiliki kinerja yang baik, karena sebagai bentuk pertanggung jawaban mereka dalam mengelola dana zakat yang disalurkan mereka untuk beribadah kepada Allah SWT tersebut.

Hal lain yang penting selain memaksimalkan penghimpunan jumlah dana zakat oleh lembaga yaitu distribusi dan pendayagunaan dana tersebut. Pendistribusian dan pendayagunaan yang baik bisa menggambarkan bahwa kinerja lembaga tersebut baik pula. Karena kedua hal tersebut penting, apabila dana terhimpun jumlahnya banyak, namun kedua hal tersebut tidak mampu dilaksanakan dengan baik maka akan percuma.

Meningkatkan atau memenuhi kekurangan kemampuan dari individu dapat dilaksanakan melalui pemenuhan maqashid syariah pada individu tersebut. As-Syatibi menawarkan teori kesejahteraan dalam maqashid syariah dengan pemeliharaan terhadap lima unsur, yaitu agama, jiwa, akal, keturunan, serta harta. Kelima unsur tersebut memiliki sekala prioritas yaitu pertama (agama) lebih utama dari unsur yang ada di urutan kedua (jiwa), begitu pula unsur yang kedua, lebih utama daripada unsur yang ketiga (akal) dan begitu seterusnya (Wibowo,2012:15).

Hal tersebut menjadi dasar dalam pengelolaan dana yang dilakukan oleh Lembaga zakat agar pengelolaan tersebut menjadi manfaat bagi penerimanya, Dengan melindungi maqashid syariah penerima dana. Saat ini lembaga zakat dalam penyalurannya dibuatlah programprogram. Program tersebut agar penyaluran dapat lebih efektif dan khususnya dalam melindungi aspek maqashid syariah dari penerima dana guna memperbaiki kualitas hidup mereka seperti yang dilakukan oleh lembaga Yayasan Dana Sosial Al Falah Surabaya.

Perlindungan terhadap aspek maqashid syariah ini dianggap penting menjadi dasar bagi lembaga zakat dalam mengelola dana melalui programprogramnya. Maqashid syariah dalam islam menjadi sebuah indikator kesejahteraan atau perbaikan kualitas hidup seseorang. Terlindunginya aspek- 
Laksono, et al/Jurnal Ekonomi Syariah Teori dan Terapan Vol. 5 No. 6 Juni 2018: 467-482; KINERJA PROGRAM KELOMPOK USAHA MANDIRI YAYASAN DANA SOSIAL AL FALAH TERHADAP PERLINDUNGAN MAQASHID SYARIAH

aspek maqashid syariah dari seseorang berarti kualitas hidup seseorang tersebut bisa dikatakan menjadi lebih baik. dengan dijadikannya maqashid syariah sebagai dasar bagi pengelolaan program tersebut maka dana yang terkelola oleh lembaga zakat tersebut akan lebih efektif dalam memberi manfaat bagi mustahianya. Berdasarkan hal tersebut maka kinerja lembaga zakat dalam melindungi maqashid syariah sangatlah menjadi hal yang vital karena pada dasarnya seseorang menunaikan zakat, infaq, shadaqah untuk menolong sesama umat muslim lainnya.

YDSF atau Yayasan Dana Sosial AlFalah Surabaya didirikan pada 1 Maret 1987, dengan prestasinya sebagai lembaga pendayagunaan dana yang amanah dan profesional menjadikannya sebagai lembaga pengelolaan zakat, infaq dan shadaqoh terpercaya di Indonesia. Dengan prestasi dan profesionalisme dari YDSF tersebut membuat sekitar 85.000 donatur tetap setiap bulannya dari berbagai kalangan dan potensi yang berbeda. Mereka turut serta dalam berkontribusi membangun negeri ini.

Program-program yang dijalankan oleh YDSF terdiri dari beberapa, salah satu program dari YDSF adalah KUM ataU Kelompok Usaha Mandiri. Dalam program Kelompok Usaha Mandiri ini YDSF memberikan sejumlah dana bantuan 
Laksono, et al/Jurnal Ekonomi Syariah Teori dan Terapan Vol. 5 No. 6 Juni 2018: 467-482; KINERJA PROGRAM KELOMPOK USAHA MANDIRI YAYASAN DANA SOSIAL AL FALAH TERHADAP

\section{PERLINDUNGAN MAQASHID SYARIAH}

Dalam Hafidhuddin (2008:14) kata

zakat menurut bahasa berasal dari kata zakaa, yang berarti bertambah dan berkembang. Selain itu, zakat mempunyai arti al-barakatu (keberkahan), an-nama' (pertumbuhan dan perkembangan), aththaharatu (kesucian), ash-shalahu (keberesan). Fikih Islam mendefinisikan zakat menurut istilah adalah "penunaian hak yang diwajibkan atas harta tertentu, yang diperuntukkan bagi orang tertentu yang kewajibannya didasari oleh haul (batas waktu) dan nishab (batas minimum).

Zakat adalah salah satu dari rukun Islam yang kelima, kewajiban zakat berupa kewajiban mengeluarkan sebagian harta yang memenuhi syarat terhadap sekelompok orang yang memiliki kelebihan harta (muzakki) dimana harta yang dikeluarkan akan disalurkan kepada golongan yang berhak menerima zakat (mustahia) yang telah ditentukan oleh syariat Islam. Penyaluran harta zakat tidaklah dapat dilakukan dengan sesuka hati, akan tetapi telah diatur oleh Islam tentang golongan-golongan yang berhak menerima zakat sebagai firman Allah SWT al-Qur'an surat At-Taubah ayat 60:

Artinya: "Sesungguhnya zakat-zakat itu, hanyalah untuk orang-orang fakir, orangorang miskin, pengurus-pengurus zakat, Para mu'allaf yang dibujuk hatinya, untuk (memerdekakan) budak, orang-orang yang berhutang, untuk jalan Allah dan untuk mereka yuang sedang dalam perjalanan, sebagai suatu ketetapan yang diwajibkan Allah, dan Allah Maha mengetahui lagi Maha Bijaksana". (Depag, 2005)

Dalam ayat di atas disebutkan terdapat 8 golongan yang berhak menerima zakat, yaitu:

1. Fakir

2. Miskin

3. Amil Zakat

4. Mu'allaf

5. Memerdekakan Budak (Riqab)

6. Orang yang berhutang (Gharim)

7. Fisabilillah

8. Orang Yang Sedang Dalam Perjalanan (Ibnu Sabil)

Suprayitno (2005:35) menjelaskan mengenai fungsi zakat yaitu bahwa zakat akan meningkatkan pendapatan orangorang miskin. Setiap tambahann pendapatan akan digunakan untuk membeli barang-barang dan jasa pokok sehingga meningkatkan permintaan agregat terhadap barang-barang dan jasa pokok tersebut. Permintaan agregat yang meningkat akan menarik peningkatan invetasi. Di sisi lain zakat juga secara agregat mendorong peningkatan tabungan dan investasi.

Hafidhuddin dalam mafrudloh (2009:11) mengatakan bahwa infaq adalah menyerahkan harta untuk kebajikan yang diperintahkan oleh Allah SWT. Zakat disebut infaq karena zakat itu adalah suatu bentuk penyerahan harta untuk kebajikankebajikan yang diperintahkan Allah SWT. Salah satu contoh pemakaian kata infaq yang menunjukkan makna zakat adalah 
Laksono, et al/Jurnal Ekonomi Syariah Teori dan Terapan Vol. 5 No. 6 Juni 2018: 467-482; KINERJA PROGRAM KELOMPOK USAHA MANDIRI YAYASAN DANA SOSIAL AL FALAH TERHADAP PERLINDUNGAN MAQASHID SYARIAH

seperti firman Allah SWT dalam surat At-

Taubah ayat 34

Artinya: hai orang-orang yang beriman, Sesungguhnya sebahagian besar dari orang-orang alim Yahudi dan rahib-rahib Nasrani benar-benar memakan harta orang dengan jalan batil dan mereka menghalang-halangi (manusia) dari jalan Allah. dan orang-orang yang menyimpan emas dan perak dan tidak menafkahkannya pada jalan Allah, Maka beritahukanlah kepada mereka, (bahwa mereka akan mendapat) siksa yang pedih, Hafidhuddin dalam Mafrudloh

(2009:11) menjelaskan Shadaqoh adalah sesuatu yang diberikan dengan tujuan untuk mendekatkan diri kepada Allah SWT. Zakat disebut shadaqoh karena memang salah satu tujuan utama zakat adalah untuk mendekatkan diri kepada Allah SWT.

Imam Qurtubi dalam Hafidhuddin (2002:125) menyatakan bahwa amil zakat adalah orang orang yang ditugaskan oleh imam/pemerintah untuk mengambil, menuliskan, menghitung dan mencatatkan zakat yang diambilnya dari para Muzakki untuk kemudian diberikan kepada yang berhak menerimanya. Peran amil tersebut saat ini dijalankan oleh Badan Amil Zakat (BAZ) atau Lembaga Amil Zakat (LAZ)

Organisasi lembaga pengelola zakat tentu memiliki fungsi yang sama, fungsinya yaitu dapat mengumpulkan dana zakat dari masyarakat dan menyalurkannya kembali dengan baik secara profesional. Kegiatan utama dari organisasi pengelola zakat, BAZ maupun LAZ telah diatur dalam UU Zakat No.23 tahun 2011. Disebutkan bahwa kegiatan utama organisasi pengelola zakat adalah pengumpulan, pendistribusian, dan pendayagunaan. Berdasarkan UU tersebut dapat disimpulkan bahwa fungsi dari lembaga pengelola zakat adalah mengumpulkan, mendistribusikan, serta mendayagunakan dana zakat.

Tugas lainnya dari pengelola adalah pendistribusian. Dalam pendistribusain zakat diatur dalam undang-undang, bahwa zakat wajib didistribusikan kepada mustahiq sesuai dengan syariat Islam.

Fungsi zakat yang terakhir adalah pendayagunaan. Dalam undangundang zakat diatur zakat dapat didayagunakan untuk usaha produktif dalam rangka penanganan fakir miskin dan peningkatan kualitas umat.

Paul dalam prijono dan Pranarka (1996) mengatakan bahwa pemberdayaan berarti pembagian kekuasaan yang adil sehingga meningkatkan kesadaran politis dan kekuasaan pada kelompok yang lemah serta memperbesar pengaruh mereka terhadap proses dan hasil-hasil pembangunan.

Saat ini pemberdayaan hanya terarah pada tercapainya tujuan yang hanya berkaitan dengan hal-hal duniawi saja seperti halnya kekayaan, penguasaan teknologi, terbentuknya sarana pra-sarana umum yang berkualitas, dll. Dalam perspektif Islam pemberdayaan harus 
Laksono, et al/Jurnal Ekonomi Syariah Teori dan Terapan Vol. 5 No. 6 Juni 2018: 467-482; KINERJA PROGRAM KELOMPOK USAHA MANDIRI YAYASAN DANA SOSIAL AL FALAH TERHADAP PERLINDUNGAN MAQASHID SYARIAH

memiliki karakteristik yang seimbang, maka pemberdayaan tidak hanya terfokus pada target yang bersifat duniawi dan materialistis saja tetapi juga akidah, ibadah, dan akhlaq.

Al-Qur'an menjelaskan tentang pemberdayaan masyarakat dalam kerangka-kerangka peran dan proses dalam QS Al-Ahzab 45-46

Artinya: Hai Nabi, Sesungguhnya Kami mengutusmu untuk Jadi saksi, dan pembawa kabar gembira dan pemberi peringatan. Dan untuk Jadi penyeru kepada agama Allah dengan izin-Nya dan untuk Jadi cahaya yang menerangi. (Depag,2005)

Maqashid syariah adalah "Maslahah yang mendasari falah, yaitu kehidupan yang mulia dan sejahtera dunia dan akhirat yang terdiri dari 5 hal yaitu agama (dien), jiwa (nafs), intelektual (aql), keluarga dan keturunan (nasl), dan harta (mal). Jika salah satu kebutuhan tidak terpenuhi dengan seimbang maka manusia tidak akan mencapai kebahagiaan hidup yang sempurna," (P3EI, 2008:6)

Sedangkan menurut Ryandono (2010:30) dalam menjaga jiwa (hifdzud nafs) diquwujudkan dalam pangan, sandang, tempat tinggal, kesehatan, dan fasilitas umum.

Sedangkan menurut Ryandono (2010:30) menjaga keturunan (hifdzun nasl) adalah meliputi tentang perkawinan, tunjangan kehamilan dan melahirkan serta menyusui, pendidikan untuk masa depan anak.

\section{Menurut Ryandono}

(2010:30) menjaga harta (hifdzul maal) meliputi pendapatan yang layak dan adil, kesempatan berusaha, kehalalan dan kethoyiban dalam rejeki, persaingan fair dan sebagainya dengan contoh, yaitu:

Dalam Manajemen Prestasi Kerja Islam (1996) dijelaskan mengenai kinerja yaitu, bahwa manusia dilahirkan kedunia kedunia ini dalam keadaan miskin tidak mempunyai harta apapun, namun Allah memberikan jalan berupa kehidupan dunia dengan segala kekayaan yang ada untuk dikelola oleh manusia melalui akal pikiran. Maka dengan akal yang Allah berikan kepada manusia, manusia dituntut untuk memanfaatkan akal yang telah diberikan dengan cara bekerja sebagai solusi kehidupan mereka.

Menurut Zadjuli (2006:19-20), islam memnpunyai beberapa unsur dalam melakukan penelitian kinerja suatu kegiatan usaha yang meliputi:

1. Niat bekerja karena Allah.

2. Dalam bekerja harus memberikan kaidah/norma/syariah secara totalitas.

3. Dalam bekerja dituntut penerapan azas efisiensi dan manfaat dengan tetap menjaga kelestarian lingkungan.

4. Mencari keseimbangan antara harta dengan ibadah.

5. Setelah berhasil dalam bekerja hendaklah bersyukur kepada Allah 
Laksono, et al/Jurnal Ekonomi Syariah Teori dan Terapan Vol. 5 No. 6 Juni 2018: 467-482; KINERJA PROGRAM KELOMPOK USAHA MANDIRI YAYASAN DANA SOSIAL AL FALAH TERHADAP PERLINDUNGAN MAQASHID SYARIAH

SWT dengan menjalankan segala perintah-Nya dengan baik dan benar.

\section{Proporsisi}

Program Kelompok Usaha Mandiri yang dikelola dengan kinerja yang baik akan mampu memberikan perlindungan terhadap maqashid syariah mustahiq melalui bantuan dan kegiatan-kegiatan yang diadakan di dalam program tersebut.

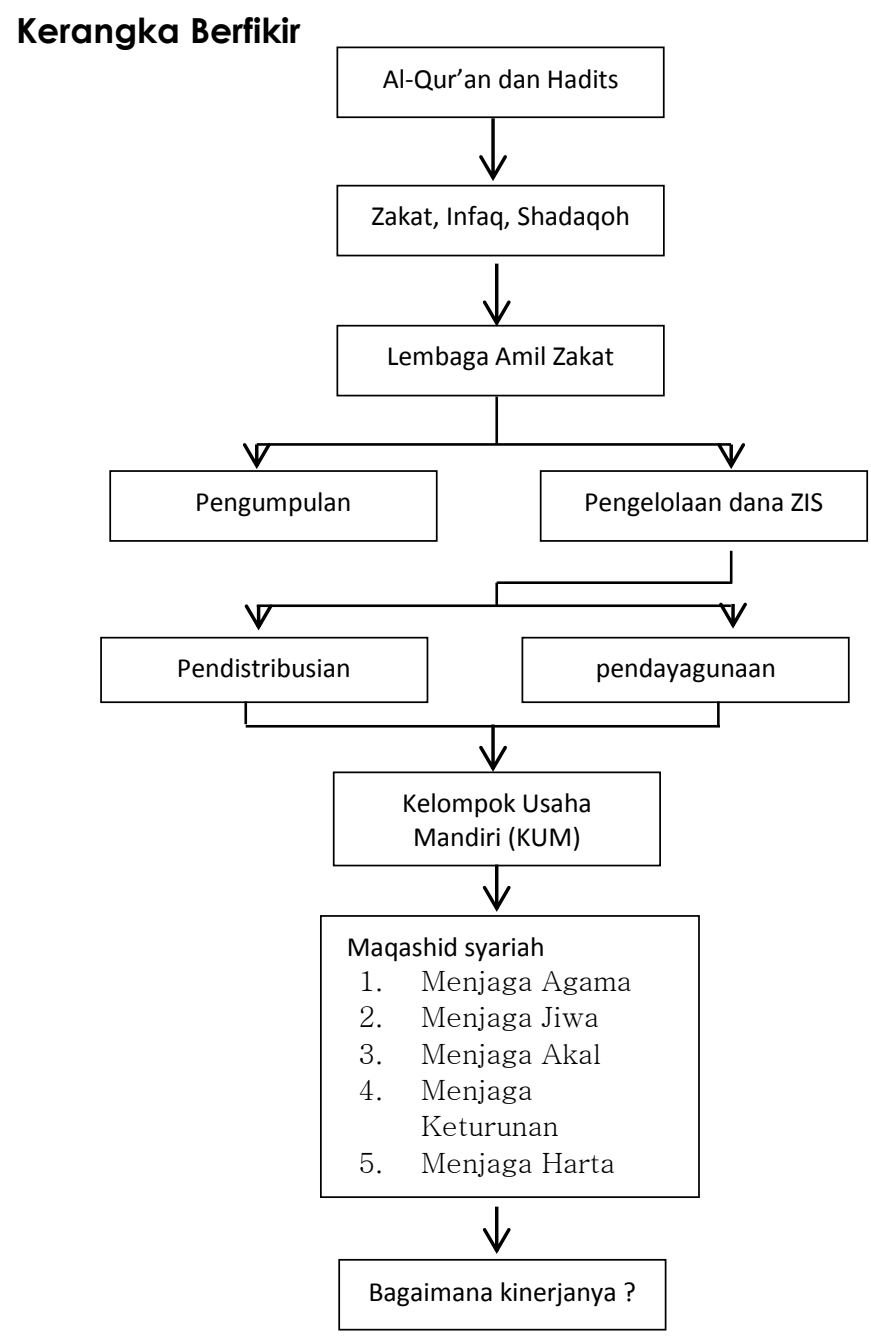

III. Metode Penelitian

Penelitian ini menggunakan

pendekatan kualitatif. Strategi yang digunakan dalam penelitian ini adalah studi kasus. Penelitian ini tidak memerlukan kontrol terhadap peristiwa yang terjadi di mana tidak ada rekayasa dan situasi yang dibuat-buat. Semua peristiwa merupakan kejadian yang real yang terjadi di lapangan tanpa ada campur tangan dari peneliti.

Penelitian yang dimaksud adalah penelitian yang dilakukan dalam rangka menjawab rumusan masalah yaitu bagaimana kinerja program Kelompok Usaha Mandiri YDSF terhadap perlindungan maqashid syariah.

- Dari ruang lingkup tersebut akan diketahi sejauh apa kinerja yang dilakukan kelompok usaha mandiriYDSF dalam melindungi maqashid syariah mustahiqnya.

Data dalam penelitian ini menggunakan data primer dan data sekunder.

Pada tahap ini, dilakukan pemeriksaan keabsahan data yang telah diperoleh selama proses pengumpulan data. Salah satu teknik yang sering digunakan dalam penelitian kualitatif adalah triangulasi. Triangulasi dilakukan untuk memperkuat data, untuk membuat peneliti yakin terhadap kebenaran dan kelengkapan data. Ada tiga macam triangulasi, yakni triangulasi sumber, triangulasi teknik pengumpulan data, dan triangulasi waktu. Dalam penelitian ini teknik triangulasi yang digunakan adalah triangulasi sumber.

Teknik analisis penjodohan pola adalah membandingkan pola yang 
Laksono, et al/Jurnal Ekonomi Syariah Teori dan Terapan Vol. 5 No. 6 Juni 2018: 467-482; KINERJA PROGRAM KELOMPOK USAHA MANDIRI YAYASAN DANA SOSIAL AL FALAH TERHADAP PERLINDUNGAN MAQASHID SYARIAH

didasarkan atas empiri dengan pola yang diprediksikan (prediksi alternatif). Jika kedua pola ini ada persamaan, maka menguatkan validitas internal studi kasus. Jika studi kasus eksploratoris, polanya berhubungan dengan variabel dependen / independen dari penelitian. Jika studi kasus deskriptif, maka penjodohan pola akan relevan dengan pola variabel-variabel spesifik yang diprediksi dan ditentukan sebelum pengumpulan data.

Dalam menganalisis kinerja dalam penelitian ini dibuat juga sebuah kategori yang terdiri dari 5 kategori yang menggambarkan kinerja dari program Kelompok Usaha Mandiri YDSF terhadap perlindungan maqashid syariah, kategori tersebut terdiri dari sangat buruk, buruk, cukup, baik, dan sangat baik. pengkategorian akan ditentukan dengan berapa aspek maqashid syariah yang dapat terlindungi melalui program Kelompk Usaha Mandiri YDSF. Setiap satu Aspek dapat diasumsikan terlindungi apabila ada program atau kegiatan yang dilakukan oleh program Kelompok Usaha Mandiri yang berhubungan dengan aspek tersebut dan memberikan manfaat bagi anggota yang berpartisipasi dalam program atau kegiatan tersebut. Sebaliknya, aspek tidak akan diasumsikan terlindungi apabila hanya terdapat sebuah program yang berkaitan dengan salah satu aspek namun tidak memberikan manfaat dan tidak ada anggota yang berpartispasi dalam program atau kegiatan tersebut.

Dari asumsi diatas berikut tabel kategori kinerja program Kelompok Usaha Mandiri YDSF.

Tabel 3.1.

Tabel kategori kinerja

\begin{tabular}{|c|c|l|}
\hline No. & $\begin{array}{c}\text { Jumlah Aspek } \\
\text { yang terlindungi }\end{array}$ & \multicolumn{1}{|c|}{$\begin{array}{c}\text { Penilaian } \\
\text { kinerja }\end{array}$} \\
\hline 1 & 1 Aspek & $\begin{array}{l}\text { Sangat } \\
\text { Buruk }\end{array}$ \\
\hline 2 & 2 aspek & Buruk \\
\hline 3 & 3 aspek & Cukup \\
\hline 4 & 4 aspek & Baik \\
\hline 5 & 5 aspek & Sangat baik \\
\hline
\end{tabular}

Kriteria manfaat diterima dan dapat melindungi salah satu aspek maqashid syariah sesuai dengan yang telah ditulis di bab 2 pada sub bab maqashid syariah.

\section{Pembahasan}

Awal berdirinya Yayasan Dana Sosial Al Falah (YDSF) Surabaya adalah dari kebiasaan ketua pengurus masjid Al Falah yaitu Alm. H. Abdul Karim. Beliau adalah salah satu pengusaha yang sukses. Rutinitas beliau setiap hari ba'da shubuh yaitu berkeliling dipinggiran kota Surabaya. Beliau sering mendapati masjid yang terbengkalai pembangunannya karena kekurangan dana. Lalu beliau mengajak para dermawan muslim jamaah Masjid Al Falah menghimpun dana untuk membantu masjid-masjid tersebut. 
Laksono, et al/Jurnal Ekonomi Syariah Teori dan Terapan Vol. 5 No. 6 Juni 2018: 467-482; KINERJA PROGRAM KELOMPOK USAHA MANDIRI YAYASAN DANA SOSIAL AL FALAH TERHADAP PERLINDUNGAN MAQASHID SYARIAH

Pada akhirnya YDSF atau Yayasan

Dana Sosial Al Falah Surabaya didirikan pada 1 Maret 1987, dengan prestasinya sebagai lembaga pendayagunaan dana yang amanah dan profesional menjadikannya sebagai lembaga pengelolaan zakat, infaq dan shadaqoh terpercaya di Indonesia. Dengan prestasi dan profesionalisme dari YDSF tersebut membuat sekitar 85.000 donatur tetap setiap bulannya dari berbagai kalangan dan potensi yang berbeda. Mereka turut serta dalam berkontribusi membangun negeri ini.

Penelitian ini adalah fokus terhadap kinerja program Kelompok Usaha Mandiri YDSF dengan indikator, seberapa mampu program ini dalam melindungi maqashid syariah oleh mustahiq yang menjadi anggotanya.

Dalam kasus ini lembaga YDSF sebagai lembaga amil mendayagunakan dana melalui salah satu programnya yaitu kelompok usaha mandiri sebagai sarana dalam mencapai sasaran yaitu meningkatkan kualitas hidup dari mustahiq atau penerima dana. Melalui program kelompok usaha mandiri YDSF melakukan upaya-upaya dalam meningkatkan kualitas hidup dari mustahiq dengan berdasarkan pada maqashid syariah.

Perlindungan terhadap agama dalam penelitian ini adalah terpenuhinya hal-hal yang berkaitan dengan pengamalan rukun Islam yang semakin meningkat. Terdapat kegiatan di dalam program kelompok usaha mandiri yang berkaitan dengan kajian keagamaan kegiatan tersebut berupa Pembinaan Rutin.

Tujuan dari kegiatan pembinaan rutin ini adalah untuk meningkatkan pengetahuan agama melalui kajian agar dapat meningkatkan kualitas keagamaan anggota komunitas. Selain itu, kajian yang dilakukan untuk menguatkan mental dan komitmen mereka dalam menekuni usaha yang sedang mereka jalani. Semakin kuat mental dan komitmen mereka menjalani usaha diharapkan semangat mereka semakin tinggi dalam meningkatkan kualitas hidup di dunia dan di akhirat.

Dalam penelitian ini peneliti mendalami program dari lain bidang yang kegiatannya berkaitan terhadap perlindungan jiwa atau yang berkaitan dengan terlindunginya kesehatan anggota program kum. Program yang berkaitan tersebut adalah program di bidang kesehatan yaitu layanan klinik sosial yang didalamnya terdapat program layanan kesehatan pasien dhuafa dan layanan operasi gratis.

Program layanan klinik sosial YDSF bertujuan untuk memperbaiki kualitas kesehatan umat, khususnya bagi kaum dhuafa yang tidak mampu berobat. Pada layanan klinik sosial ini mereka yang tidak mampu akan mendapatkan pelayanan kesehatan gratis karena seluruh biaya telah disubsidi penuh oleh YDSF. Pengobatan- 
Laksono, et al/Jurnal Ekonomi Syariah Teori dan Terapan Vol. 5 No. 6 Juni 2018: 467-482; KINERJA PROGRAM KELOMPOK USAHA MANDIRI YAYASAN DANA SOSIAL AL FALAH TERHADAP PERLINDUNGAN MAQASHID SYARIAH

pengobatan gratis yang telah dilaukan

YDSF dalam program klinik layanan sosial ini antara lain adalah operasi gratis dan layanan pengobatan umum.

Perlindungan terhadap akal dalam penelitian ini adalah terpenuhinya hal-hal yang berkaitan dengan pelatihan dan pengembangan diri anggota. Terdapat kegiatan di dalam program kelompok usaha mendiri yang berkaitan dengan pelatian dan pengembangan diri anggota kelompok usaha mandiri, kegiatan tersebut berupa pelatihan anggota komunitas. Kegiatan ini diselenggarakan untuk meningkatkan skill dan mengembangkan potensi dari anggota kelompok usaha mandiri tersebut. Kegiatan pelatihan anggota ini dibedakan menjadi 2 jenis, yaitu pelatihan yang diadakan oleh Kelompok usaha mandiri YDSF dan komunitas Kelompok usaha mandiri itu sendiri.

Di dalam program kelompok usaha mandiri, tidak terdapat kegiatan yang secara langsung berkaitan terhadap Perlindungan Keturunan, dalam penelitian ini perlindungan keturunan adalah terlindunginya akan hal-hal yang berkaitan dengan keberlangsungan pendidikan anak dari mustahiq. Program yang berkaitan tersebut adalah program bidang pendidikan yaitu PENA (Peduli Anak Bangsa). Terintegrasinya program KUM dengan program lainnya, anggota dari program KUM tersebut memiliki akses pada program PENA guna mendapatkan fasilitas beasiswa dari program tersebut.

Dalam penelitian ini perlindungan terhadap harta adalah berkaitan dengan mampunya seseorang mendapatkan pendapatan yang layak. Program KUM sendiri adalah program yang memiliki konsep memperbaiki ekonomi dari seseorang, maka program KUM ini adalah program yang berkaitan dalam perlindungan harta seseorang yang dalam penelitian ini adalah layaknya pendapatan bagi seseorang.

KUM sebagai program yang memberikan bantuan modal, tidak mewajibkan modal yang diberikan untuk dikembalikan oleh anggota. Tidak ada jaminan apapun untuk seorang mendapatkan bantuan modal KUM, namun kesadaran yang tinggi dari para anggota selama ini modal yang diberikan dikembalikan pada KUM dan beberapa dari mereka bahkan menambahkan sedekah saat pengembalian dana.

Upaya program KUM dalam melindungi maqashid syariah yang memiliki manfaat dapat membantu dan berguna bagi para anggota program KUM. Pada penelitian ini terdapat lima indikator aspek maqashid syariah yakni agama, jiwa, akal, keturunan, dan harta. Upaya program KUM dalam melindungi maqashid syariah dalam aspek agama berupa kajian keagamaan dan pembinaan rutin, kelima informan dapat memperoleh manfaat dari program 
Laksono, et al/Jurnal Ekonomi Syariah Teori dan Terapan Vol. 5 No. 6 Juni 2018: 467-482; KINERJA PROGRAM KELOMPOK USAHA MANDIRI YAYASAN DANA SOSIAL AL FALAH TERHADAP PERLINDUNGAN MAQASHID SYARIAH

tersebut berupa pengetahuan keagamaan, meningkatkan ketaqwaan dan keimanan para informan. Aspek yang kedua yakni jiwa, dalam aspek ini upaya program KUM dalam melindungi maqashid syariah berupa layanan klinik sosial yang didalamnya terdapat program layanan kesehatan pasien dhuafa dan layanan operasi gratis. Namun dari aspek ini tidak semua informan mendapatkan manfaat, hanya informan ketiga yang mengikuti program ini dengan mendapatkan bantuan operasi katarak dan bantuan vang tunai untuk pengobatan.

Upaya program KUM dalam melindungi maqashid syariah ketiga yaitu aspek akal, dalam aspek akal KUM memiliki program pelatihan dan pengembangan diri untuk para anggotanya. Pelatihan yang diadakan oleh YDSF berupa pelatihan membuat kue kering dan manajemen keuangan. Kegiatan tersebut mampu membantu kelima informan untuk mengelola keuangan mereka dengan baik, dan untuk skill membuat kue kering tetap mereka terapkan hanya saja terhalangi dengan mahalnya harga peralatan untuk pembuatan kue kering tersebut.

Upaya program KUM dalam melindungi maqashid syariah keempat adalah aspek keturunan yakni terlindunginya akan hal-hal yang berkaitan dengan keberlangsungan pendidikan anak dari anggota (mustahiq). Dalam program ini YDSF menyediakan beasiswa seperti PETA,
OTA, Non OTA, dan Back to School. Namun untuk aspek ini, kelima informan tidak mendapatkan manfaatnya dikarenakan keturunan/anak dari para informan telah usai mengenyam masa sekolah mereka. Dan aspek yang terakhir yakni harta, dalam aspek ini upaya KUM dalam melindungi maqashid syariah berupa memberikan bantuan modal, tidak mewajibkan modal yang diberikan untuk dikembalikan oleh anggota. Dari kelima informan, aspek harta mampu memberikan manfaat yang dapat merubah perekonomian dan taraf hidup mereka. Sehingga keseluruhan informan merasakan manfaat yang sangat positif dari program ini.

Pada bab 3 telah dijelaskan mengenai tabel penilaian kinerja program KUM pada YDSF. Dari tabel tersebut akan diperoleh hasil kinerja program dari masingmasing informan, yang kemudian akan ditarik kesimpulan secara keseluruhan mengenai penilaian kinerja program tersebut, berikut kategori yang akan digunakan untuk melakukan penilian kinerja:

Tabel kategori kinerja

\begin{tabular}{|l|c|l|}
\hline No. & $\begin{array}{c}\text { Jumlah Aspek } \\
\text { yang terlindungi }\end{array}$ & \multicolumn{1}{|c|}{$\begin{array}{c}\text { Penilaian } \\
\text { kinerja }\end{array}$} \\
\hline 1 & 1 Aspek & Sangat Buruk \\
\hline 2 & 2 aspek & Buruk \\
\hline 3 & 3 aspek & Cukup \\
\hline 4 & 4 aspek & Baik \\
\hline 5 & 5 aspek & Sangat baik \\
\hline
\end{tabular}


Laksono, et al/Jurnal Ekonomi Syariah Teori dan Terapan Vol. 5 No. 6 Juni 2018: 467-482; KINERJA PROGRAM KELOMPOK USAHA MANDIRI YAYASAN DANA SOSIAL AL FALAH TERHADAP PERLINDUNGAN MAQASHID SYARIAH

Tebel 4.2

Mengacu pada tabel di atas, akan dijelaskan hasil penilitian terhadap masingHasil Penilian Kinerja dari Apek yang terlindungi pada tiap Informan masing informan untuk mengetohuitorman penilaian kinerja berdasarkan jumlah aspefkorman 1 yang terlindungi. Untuk informan pertama $\ln ^{\text {Ifrman } 2}$ dan informan kedua hanya mengikufi InBrman 4 program yang ada pada KUM, program tersebut tergolong dalam aspek agama, aspek akal, dan aspek harta. Sehingga dari informan pertama dan informan kedua didapatkan hasil 3 aspek yang hanya terlindungi dan termasuk penilaian kinerja dalam kategori cukup.

Hasil dari jumlah aspek yang terlindungi pada informan ketiga sebanyak 4 dari 5 program yang ada. Program tersebut termasuk dalam aspek agama, aspek jiwa, aspek akal dan aspek harta. Untuk penilaian kinerja dari 4 aspek yang terlindungi tergolong dalam kategori baik. Kemudian untuk informan keempat dan kelima hanya mengikuti 3 program dari 5 program yang ada. Program yang diikuti oleh informan keempat dan informan kelima tergolong dalam aspek agama, aspek akal dan aspek harta. Dari jumlah aspek yang terlindungi tersebut penilaian kinerja yang diperoleh program KUM temasuk dalam kategori cukup.

Dari penjelasan tersebut, peniliti akan meringkas dan menyajikan dalam tabel 4.2 guna lebih memudahkan untuk melihat hasil dari jumlah aspek yang terlindungi dari masing-masing informan.

\begin{tabular}{|c|c|c|c|c|c|c|}
\hline \multicolumn{5}{|c|}{ Aspek yang terlindungi } & \multirow{2}{*}{ Jumlah } & \multirow{2}{*}{$\begin{array}{l}\text { Peniliar } \\
\text { Kinerja }\end{array}$} \\
\hline Agama & Jiwa & Akal & Keturuan & Harta & & \\
\hline$\sqrt{ }$ & - & $\sqrt{ }$ & - & $\sqrt{ }$ & 3 Aspek & Cukup \\
\hline$\sqrt{ }$ & - & $\sqrt{ }$ & - & $\sqrt{ }$ & 3 Aspek & Cukup \\
\hline$\sqrt{ }$ & $\sqrt{ }$ & $\sqrt{ }$ & - & $\sqrt{ }$ & 4 Aspek & Baik \\
\hline$\sqrt{ }$ & - & $\sqrt{ }$ & $\begin{array}{ll}- \\
-\end{array}$ & $\sqrt{ }$ & 3 Aspek & Cukup \\
\hline$\sqrt{ }$ & - & $\sqrt{ }$ & - & $\sqrt{ }$ & 3 Aspek & Cukup \\
\hline
\end{tabular}

Sumber: data telah diolah

Hasil penelitian dari 5 informan memberikan hasil yang berbeda-beda, dari informan pertama hingga informan kelima. Untuk menjawab rumusan masalah pada bab 1 "Bagaimana Kinerja Kinerja Program Kelompok Usaha Mandiri (KUM) Yayasan Dana Sosial Al-Falah dalam Perlindungan terhadap Maqashid Syariah?" Secara keseluruhan kemampuan dari program Kelompok Usaha Mandiri (KUM) dalam melindungi maqashid syariah melalui program-program yang mereka miliki termasuk dalam penilaian katergori cukup. Kategori cukup yang didapatkan berasal dari 3 aspek yang dalam dilindungi antara lain, aspek agama, aspek akal dan aspek harta. Ketiga aspek tersebut terdapat program-program yang telah diikuti dan diperoleh manfaatnya bagi kelima informan. Manfaat yang didapatkan tidak hanya berupa materi namun juga berupa moral dan kesehatan.

Terdapat beberapa keterbatasan yang dialami oleh penulis dalam melakukan penelitian ini, berikut adalah keterbatasan penelitian yang dialami oleh penulis 
Laksono, et al/Jurnal Ekonomi Syariah Teori dan Terapan Vol. 5 No. 6 Juni 2018: 467-482; KINERJA PROGRAM KELOMPOK USAHA MANDIRI YAYASAN DANA SOSIAL AL FALAH TERHADAP

PERLINDUNGAN MAQASHID SYARIAH

1. Tidak terdapat data lengkap mengenai setiap mustahiq KUM, data mengenai mustahiq hanya sebatas data diri mustahiq saja.

2. Beberapa koordinator kelompok tidak bersedia untuk diwawancarai untuk penelitian ini.

3. Informan dari pihak YDSF hanya sampai manager, tidak pada kedudukan tertingginya.

\section{Simpulan dan Saran}

Berikut simpulan yang dihasilkan dari penelitian ini, di antaranya:

1. Program kelompok usaha mandiri Yayasan Dana Sosial Al-Falah memiliki kinerja yang cukup terhadap perlindungan maqashid syariah. Kinerja program kelompok usaha mandiri tersebut diukur dengan indikator seberapa mampu program kelompok usaha mandiri melalui kegiatannya dalam melindungi kelima aspek maqashid syariah yaitu aspek Agama, jiwa, akal, keturunan, dan harta. Kinerja cukup tersebut tergambar dengan program kelomok usaha mandiri YDSF tersebut mampu melindungi 3 aspek maqashid syariah, yaitu aspek agama, akal, dan harta.

2. Kinerja yang cukup dari program Kelompok usaha mandiri YDSF terlihat dengan terpenuhinya pada sebagian aspek maqashid syariah pada mustahiq yang menjadi anggota dari kelompok usaha mandiri tersebut melalui kegiatan-kegiatan yang dilaksanakan yaitu pembinaan keagamaan, menambah ilmu anggota melalui pelatihan, dan juga kelompok usaha mandiri terintegrasi dengan program YDSF lainnya yang berkaitan dengan pendidikan maupun kesehatan.

Berikut adalah saran yang diharapkan dari penelitian ini, di antaranya:

1. Diharapkan ada penelitian lanjutan yang lebih mendalam dan menyeluruh mengenai kinerja lembaga amil zakat ydsf dalam mengelola dana zis dalam perlindungan maqashid syariah mustahiq-nya.

2. Diharapkan YDSF mampu memberikan kegiatan didalam program kelompok usaha mandiri dalam perlindungan maqashid syariah yang tertuju secara langsung pada anggota kelompok usaha mandiri.

3. Diharapkan YDSF mampu memberikan modal usaha yang lebih besar pada anggotanya agar memberikan perkembangan usaha yang lebih signifikan dan mustahiq mendapat manfaat yang lebih besar dari modal usaha tersebut.

\section{DAFTAR PUSTAKA}

Al-Qur'an. Departemen Agama Republik
Indonesia, Edisi Baru Cetakan
2005.Jakarta: Pustaka Amani
Jakarta.


Laksono, et al/Jurnal Ekonomi Syariah Teori dan Terapan Vol. 5 No. 6 Juni 2018: 467-482; KINERJA PROGRAM KELOMPOK USAHA MANDIRI YAYASAN DANA SOSIAL AL FALAH TERHADAP

PERLINDUNGAN MAQASHID SYARIAH

Ali Hasan, M. 2008. Zakat dan Infak Salah

satu solusi mengatasi problema sosial

di indonesia. Jakarta: Kencana prenda media grup.

Bungin, M Burhan. 2007. Penelitian kualitatif: komunikasi ekonomi, Kebijakan publik, dan ilmu sosial lainnya. Jakarta: Kencana Prenada Media Grup.

Djamil, Faturrahman. 1995. Metode Majelis Tarji Muhammadiyah. Jakarta: Logos.

Hafidhuddin, Didin. 2002. Zakat Dalam Perekonomian Modern. Jakarta: Gema Insani Press.

Hasibuan, M. 2001. Manajemen Sumber Daya Manusia. Jakarta: Bumi Aksara.

Jaelani, A. (2008). Pengaruh kualitas pelayanan dan social marketing lembaga amil (LAZ) terhadap keputusan ber zakat muzakki (studi kasus: pada rumah zakat Indonesia). Master's thesis, Jakarta: Universitas Indonesia.

Mafrudloh, Shoimataul. 2009. Analisis FaktorFaktor yang Mempengaruhi Pengumpulan Dana ZIS pada Lembaga Pengelolaan Dana Zakat di Provinsi Jatim. Skripsi tidak diterbitkan. Surabaya: Universitas Airlangga Surabaya.

Mangkunegara, Anwar Prabu. 2010.

Evaluasi Kinerja Karyawan SDM. Refika Jakarta: Aditama.
Miles and Huberman. 1992. Qualitative Data Analysis. California: Sage Publication Inc.

Moleong. 2002. Metode Penelitian Kualitatif. Bandung: PT Rosda Karya.

Nazir, Muhammad. 2005. Metode penelitian. Bogor: Ghalia Indonesia.

Onny S, Prijono dan Pranarka A M W. 1996. Pemberdayaan : Konsep, Kebijakan dan Implementasi. Jakarta: CSIS.

P3El. 2008. Ekonomi islam. Jakarta: Rajawali Press.

Qardhawi, Yusuf. 1999. Hukum Zakat. Jakarta: PT Pustaka Litera Antar Nusa.

Ryandono, Muhammad Nafik Hadi. 2010. Ringkasan disertasi: peran dan pengaruh penghimpunan dana terhadap penyaluran dana dan faktor kinerja bank serta kesejahteraan karyawan bank islam di indonesia.

Stonner, James A F. 1996. Manajemen. Edisi II. Jakarta: Prenhalindo.

Sugiyono. 2009. Memahami Penelitian Kualitatif. Bandung: Alfabeta

Sulistiyani, Ambar Teguh. 2003. Manajemen Sumber Daya Manusia. Yogyakarta: Graha llmu.

Sumodiningrat, Gunawan. 2002. Memberdayakan Masyarakat 
Laksono, et al/Jurnal Ekonomi Syariah Teori dan Terapan Vol. 5 No. 6 Juni 2018: 467-482; KINERJA PROGRAM KELOMPOK USAHA MANDIRI YAYASAN DANA SOSIAL AL FALAH TERHADAP PERLINDUNGAN MAQASHID SYARIAH

Perencana. Jakarta: Kencana

Nusadwina.

Suprayitno, Eko. 2005. Ekonomi Islam:

Pendekatan Ekonomi Makro Islam

dan Konvensional. Yogyakarta:

Graha llmu.

Suyanto, M. 2008. Muhammad Business and Strategy Ethics. Yogyakarta. Andi Offset.

Tasmara, Toto. 2008. Membudayakan Etos Kerja Islami. Jakarta: Gema Insani.

Yin, Robert K. 2012. Studi Kasus Desain dan Metode. Jakarta: PT Raja Grafindo Persada. 